\title{
Antiplatelet versus oral anticoagulant therapy as antithrombotic prophylaxis after mitral valve repair
}

\author{
Domenico Paparella, MD, ${ }^{\mathrm{a}}$ Michele Di Mauro, MD, ${ }^{\mathrm{b}}$ Keren Bitton Worms, MD, ${ }^{\mathrm{c}}$ Gil Bolotin, MD, \\ Claudio Russo, MD, ${ }^{\mathrm{d}}$ Salvatore Trunfio, MD, ${ }_{\mathrm{d}}^{\mathrm{d}}$ Roberto Scrofani, MD, ${ }_{\mathrm{e}}$ Carlo Antona, MD, ${ }^{\mathrm{e}}$ \\ Guglielmo Actis Dato, MD, ${ }^{\mathrm{f}}$ Riccardo Casabona, MD, ${ }^{\mathrm{f}}$ Andrea Colli, MD, ${ }^{\mathrm{g}}$ Gino Gerosa, MD, ${ }^{\mathrm{g}}$ \\ Attilio Renzulli, MD, ${ }^{\mathrm{h}}$ Filiberto Serraino, MD,${ }^{\mathrm{h}}$ Giuseppe Scrascia, MD, PhD, ${ }^{\mathrm{i}}$ Salvatore Zaccaria, MD, ${ }^{\mathrm{i}}$ \\ Michele De Bonis, MD, ${ }^{\mathrm{j}}$ Maurizio Taramasso, MD,${ }^{\mathrm{j}}$ Luis Delgado, MD, ${ }^{\mathrm{k}}$ Francesco Tritto, MD, \\ Joseph Marmo, MD, ${ }^{1}$ Alessandro Parolari, MD,${ }^{\mathrm{m}}$ Veronika Myaseodova, MD, ${ }^{\mathrm{n}}$ Emmanuel Villa, MD, \\ Giovanni Troise, MD, ${ }^{\circ}$ Francesco Nicolini, MD, ${ }^{\mathrm{p}}$ Tiziano Gherli, MD,${ }^{\mathrm{p}}$ Richard Whitlock, MD, PhD,${ }^{\mathrm{q}}$ \\ Manuela Conte, MD, ${ }^{\mathrm{a}}$ Fabio Barili, MD, ${ }^{\mathrm{r}}$ Sandro Gelsomino, MD, ${ }^{\mathrm{s}}$ Roberto Lorusso, MD, PhD, \\ Edoardo Sciatti, MD, ${ }^{\mathrm{t}}$ Daniele Marinelli, MD, ${ }^{\mathrm{u}}$ Gabriele Di Giammarco, MD, ${ }^{\mathrm{u}}$ \\ Antonio Maria Calafiore, MD, ${ }^{\mathrm{v}}$ Azmat Sheikh, MD, ${ }^{\mathrm{v}}$ Juan Jaime Alfonso, RA, ${ }^{\mathrm{v}}$ Mattia Glauber, MD, ${ }^{\mathrm{w}}$ and \\ Antonio Miceli, MD, ${ }^{\mathrm{W}}$ on behalf of the GIROC Investigators
}

\begin{abstract}
Objective: To verify the rate of thromboembolic and hemorrhagic complications during the first 6 months after mitral valve repair and to assess whether the type of antithrombotic therapy influenced clinical outcome.

Methods: Retrospective data were retrieved from 19 centers. Inclusion criteria were isolated mitral valve repair with ring implantation. Exclusion criteria were ongoing or past atrial fibrillation and any combined intraoperative surgical procedures. The study cohort consisted of 1882 patients (aged $58 \pm 15$ years; 36\% women), and included 1517 treated with an oral anticoagulant (VKA group) and 365 with antiplatelet drugs (APLT group). Primary efficacy outcome was the incidence of arterial thromboembolic events within 6 months and primary safety outcome was the incidence of major bleeding within 6 months. Propensity matching was performed to obtain 2 comparable cohorts (858 vs 286).
\end{abstract}

Results: No differences were detected for arterial embolic complications in matched cohort (1.6\% VKA vs $2.1 \%$ APLT; $P=.50)$. Conversely, patients in the APLT group showed lower incidence of major bleeding complications $(3.9 \%$ vs $0.7 \% ; P=.01)$. Six-month mortality rate was significantly higher in the VKA group $(2.7 \%$ vs $0.3 \% ; P=.02)$. Multivariable analysis in the matched cohort found VKA as independent predictor of major bleeding complications and mortality at 6 months.

Conclusions: Vitamin $\mathrm{K}$ antagonist therapy was not superior to antiplatelet therapy to prevent thromboembolic complications after mitral valve repair. Our data suggest that oral anticoagulation may carry a higher bleeding risk compared with antiplatelet therapy, although these results should be confirmed in an adequately powered randomized controlled trial. (J Thorac Cardiovasc Surg $2016 ; 151: 1302-8)$

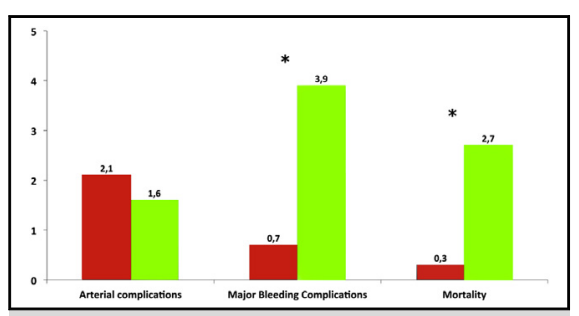

Main 6-months events in patients receiving vitamin $\mathrm{K}$ antagonists (green) and antiplatelet therapy (red) in matched cohorts.

\section{Central Message}

Oral anticoagulation is not superior to antiplatelet therapy to prevent thromboembolic complications after mitral valve repair.

\section{Perspective}

Antithrombotic prophylaxis after mitral valve repair is debated. Our study shows that vitamin $\mathrm{K}$ antagonists are not superior to antiplatelet therapy during the first 6 postoperative months to prevent thromboembolic complications. Our data suggest that oral anticoagulation may carry a higher bleeding risk compared with antiplatelet therapy. A large prospective randomized trial is needed.

See Editorial Commentary page 1309.
Mitral regurgitation is the most frequent pathology of the mitral valve in Western countries ${ }^{1}$ and mitral valve repair (MVR) is the surgical treatment of choice. ${ }^{2}$ In fact, MVR is now being performed more frequently than mitral valve replacement with biological or mechanical prosthesis ${ }^{3}$ and should be preferred to mitral valve replacement even in complex anatomic situations. ${ }^{4}$ MVR is performed using a variety of techniques depending on the etiology. In degenerative mitral insufficiency (type II, according to Carpentier classification), leaflet resections, artificial chorda tendinae implant, chordal transposition, or edge-to-edge technique are among the most frequently used. An annuloplasty ring is almost invariably implanted during MVR to reduce annular dimensions, improve leaflet coaptation, and stabilize MVR results. The artificial surface of newly implanted mitral rings takes generally 3 months to be covered by endothelium. Theoretically during this period, the ring, together with surgical knots, scarred tissue of the left atrium, and 

Abbreviations and Acronyms
APLT $=$ antiplatelet therapy
MVR $=$ mitral valve repair
$\mathrm{VKA}=$ vitamin $\mathrm{K}$ antagonist

Scanning this QR code will take you to supplemental data for this article.

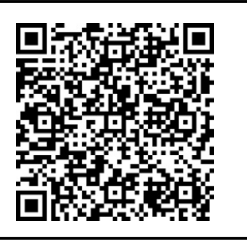

arrhythmias may increase the risk of thromboembolic complications and therefore an antithrombotic prophylaxis is usually prescribed. Whether to use oral anticoagulation with a vitamin $\mathrm{K}$ antagonist (VKA) or antiplatelet therapy (APLT) is still debated and current guidelines are discordant on this topic. ${ }^{5,6}$

In a retrospectively collected large cohort of consecutive patients who had undergone mitral valve repair in different hospitals, we aimed to verify the rate of thromboembolic and hemorrhagic complications during the first 6 months after hospital discharge, and whether the type of antithrombotic therapy influenced the clinical outcome.

\section{METHODS}

\section{Patient Cohort and Data Collection}

Nineteen centers from Italy, Spain, Canada, Israel, and Saudi Arabia participated in the study. Data were collected from institutional databases or patient charts for preoperative, operative, and postoperative details. Follow-up was achieved through direct or telephone interview with survivors, with relatives, with general practitioners, or with hospital doctors in the case of patients hospitalized for any cause after surgery. The study was conducted according to the Declaration of Helsinki. Ethics committee approval was obtained initially from the coordinating center (Policlinico of Bari University Hospital No. 759 2013-09-24) and subsequently from each participating site.

The choice of antithrombotic prophylaxis was based solely on center or surgeon preference; there were no other indication for APLT or oral anticoagulant therapy.

From the ${ }^{\mathrm{a} U}$ U.O. di Cardiochirurgia Università di Bari Aldo Moro, Italy; ${ }^{\mathrm{b}}$ U.O. Cardiologia Università dell'Aquila, Italy; ' Department of Cardiac Surgery, Rambam Medical Centre, Haifa, Israel; ${ }^{\mathrm{d}}$ U.O. Cardiochirurgia Ospedale Niguarda Milano, Italy; ${ }^{\mathrm{e}}$ U.O. di Chirurgia Cardiovascolare, Ospedale Polo Universitario Luigi Sacco, Milano, Italy; ${ }^{\mathrm{f}}$ U.O. Cardiochirurgia, Ospedale Mauriziano, Torino, Italy; ${ }^{\mathrm{g}}$ U.O. di Cardiochirurga, Dipartimento di Scienze Cardio-toraco-vascolare, Università di Padova, Italy; ${ }^{\mathrm{h}}$ Divisione di Cardiochirurgia, Università della Magna Grecia, Catanzaro, Italy; ${ }^{\mathrm{i}}$ U.O. Cardiochirurgia, Ospedale Vito Fazzi, Lecce, Italy; ${ }^{\mathrm{j}}$ U.O. Cardiochirurgia, Ospedale San Raffele, Milano, Italy; ${ }^{\mathrm{k}}$ Ospedale Universitario Germans Trias Y Pujol, Badalona, Spagna; ${ }^{1}$ U.O. Cardiochirurgia, Ospedale S. Anna E S. Sebastiano, Caserta, Italy; ${ }^{\mathrm{m}}$ Divisione di Cardiochirurgia, IRCCS San Donato, San Donato Milanese, Italy; ${ }^{\mathrm{n}}$ Unità di Ricerca Clinica in Aterotrombosi, Centro Cardiologico Monzino, Milano, Italy; ${ }^{\circ}$ Divisione di cardiochirurgia, Ospedale Poliambulanza, Brescia, Italy; ${ }^{\mathrm{P} U n i t a ̀ ~ d i ~ C a r d i o c h i r u r g i a, ~ D i p a r t i m e n t o ~ d i ~ M e-~}$ dicina Clinica e Sperimentale, Università di Parma, Italy; ${ }^{\mathrm{q}}$ Division of Cardiac Surgery, McMaster University, Hamilton, Ontario, Canada; ${ }^{\mathrm{r} D i v i s i o n}$ of Cardiac

\section{Study Design}

This is a retrospective analysis of patients having MVR as the sole valvular procedure done at participating centers during a 3-year period (from 2011-2013), with a follow-up of at least 6 months after surgery. Study cohort (Figure 1) consisted of 1882 patients and included 1517 treated with oral anticoagulant (VKA group) for first postoperative 3 months and 365 with antiplatelet drugs (aspirin $100 \mathrm{mg}$ daily, APLT group).

\section{Inclusion Criteria}

Included patients were aged $\geq 18$ years at time of surgery underwent isolated MVR with mitral ring implantation to treat mitral regurgitation, and in sinus rhythm at hospital discharge.

\section{Exclusion Criteria}

Exclusion criteria included any history of atrial fibrillation, any combined surgical procedure associated with mitral valve repair, and treatment with both oral anticoagulation and APLT ( 80 or $100 \mathrm{mg}$ once daily).

\section{Primary Outcomes}

Efficacy. This primary outcome was defined as real incidence of arterial thromboembolic events within 6 months after mitral valve repair, including cerebrovascular accidents, transient ischemic attack, and limb or mesenteric ischemic events.

Safety. This primary outcome was defined as real incidence of major bleeding up to 6 months after mitral valve repair or the stop of VKA anticoagulation +1 day, whichever came first.

\section{Definitions of Study Outcomes}

Arterial event. An arterial event was defined as the presence of 1 of the following within 6 months of the mitral valve operation: cardiac valvular or mural thrombus confirmed by echocardiogram, intracranial event confirmed by computed tomography/magnetic resonance imaging, transient ischemic attack, or limb or mesenteric thromboembolic event confirmed by arteriogram, magnetic resonance imaging, or computed tomography.

Bleeding. Major bleeding within the first 48 hours after surgery was defined per the Bleeding Academic Research Consortium ${ }^{7}$ : perioperative intracranial bleeding within 48 hours, and/or reoperation after closure of sternotomy for the purpose of controlling bleeding, and/or transfusion of $\geq 5$ units whole blood or packed red blood cells within a 48-hour period (cell saver products were not counted), and/or chest tube output $\geq 2 \mathrm{~L}$ within a 24-hour period.

Major bleeding that occurred at least 48 hours after surgery was defined per the International Society of Thrombosis and Haemostasis definition ${ }^{8}$ : fatal bleeding; and/or symptomatic bleeding in a critical area or organ, such as intracranial, intraspinal, intraocular, retroperitoneal,

Surgery, Santa Croce hospital, Cuneo, Italy; ${ }^{\text {s} E x p e r i m e n t a l ~ S u r g e r y, ~ H e a r t ~ a n d ~ V e s-~}$ sels Department, Careggi Hospital, Firenze, Italy; 'U.O. Cardiochirurgia, Spedali

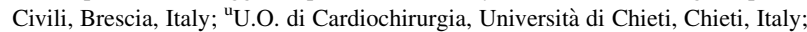
${ }^{v}$ Department of Adult Cardiac Surgery, Prince Sultan Cardiac Center, Riyadh, Saudi Arabia; and ${ }^{\mathrm{w}}$ U.O. Cardiochirurgia, Ospedale Monasterio, Massa, Italy. Source of funding: The study was not supported by specific funding.

Received for publication June 9, 2015; revisions received Nov 25, 2015; accepted for publication Dec 16, 2015; available ahead of print Jan 29, 2016.

Address for reprints: Domenico Paparella, MD, Dipartimento d'Emergenza e Trapianti d'Organo, Sezione di Cardiochirurgia, Universitá degli Studi di Bari Aldo Moro, Piazza Giulio Cesare 11, 70122 Bari, Italy (E-mail: domenico. paparella@uniba.it).

$0022-5223 / \$ 36.00$

Copyright (C) 2016 by The American Association for Thoracic Surgery

http://dx.doi.org/10.1016/j.jtcvs.2015.12.036 


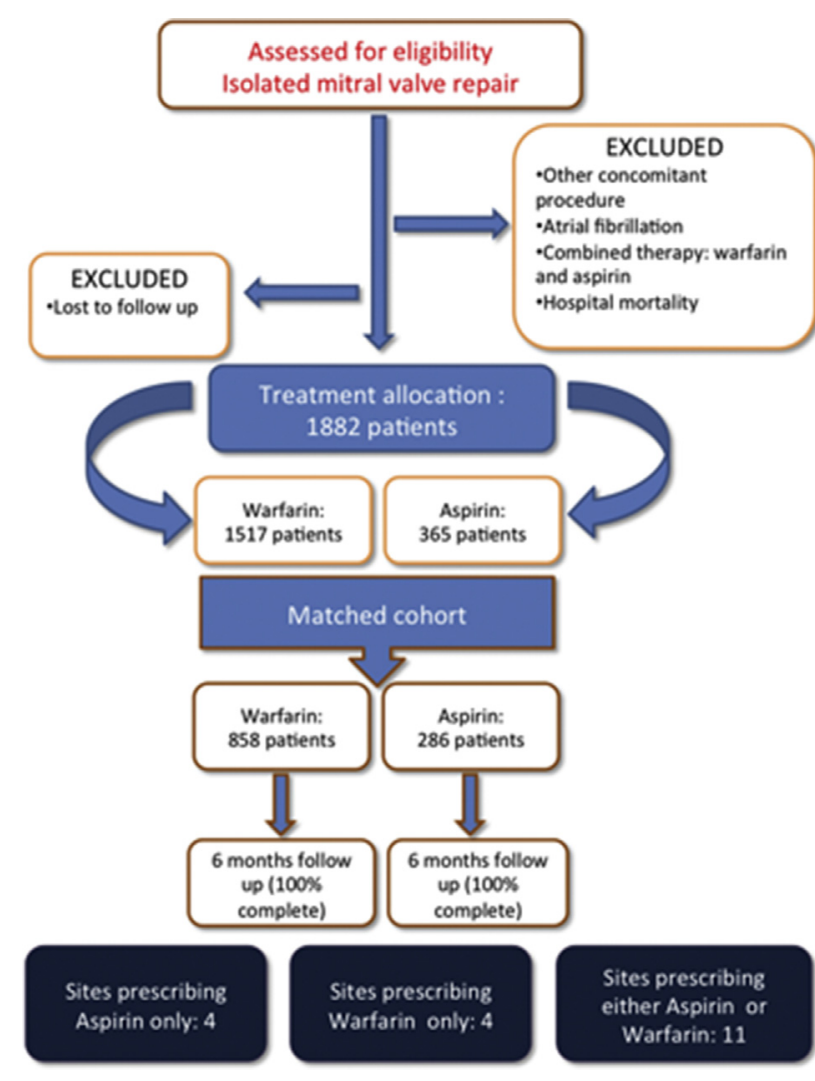

FIGURE 1. Consort diagram of the study.

intra-articular or pericardial, or intramuscular with compartment syndrome; and/or bleeding causing a fall in hemoglobin level of $3.0 \mathrm{~g} / \mathrm{dL}$ or more or leading to transfusion of 2 or more units of whole blood or red cells.

\section{Statistical Analysis}

The categorical variables are expressed as percentages, whereas the continuous variables tested for type of distribution by means of Kolmogorov-Smirnov test and were reported as the mean \pm standard deviation in case of normal distribution or as median and quartiles in case of nonnormal distribution. The comparison between the 2 groups was made by Student $t$ test for independent variables or Mann-Whitney $U$ test in case of continuous variables. Frequencies were compared using the $\chi^{2}$ or Fisher exact test.

A not parsimonious propensity score model was built having APLT as the treatment (area under the curve, 0.96).

A 1:3 sample matching was performed using propensity score caliper matching with a caliper of 0.2 . The final propensity model is reported in Appendix 1. To validate the matching, standardized mean differences after matching as well as $P$ values are reported in Table 1. Standardized mean difference $\leq 20 \%$ was considered a threshold for a good balance.

All the variables reported in Table 1 were tested using univariate analysis to predict either major bleeding or mortality; when the $P$ value was $<0.2$, the variable was included in the initial logistic regression models. The results of multivariable analyses were reported as odds ratios and $95 \%$ confidence intervals, and $P$ value. Receiver operating characteristic curve analysis was used to assess the calibration of the final models. SPSS version 20 software (IBM-SPSS Inc, Chicago Ill) integrated with R software version 2.1 (R Foundation for Statistical Computing, Vienna, Austria) was used to obtain automatically the best-matched samples.

\section{RESULTS}

The study cohort consisted of 1882 patients (aged $58 \pm 15$ years; $36 \%$ women), and included 1517 patients treated with VKA (VKA group) and 365 treated with antiplatelet drugs (APLT group).

After propensity matching the 2 groups consisted of 858 VKA and 286 APLT patients, respectively.

Table 1 shows patient characteristics according to the groups in the matched cohort. As reported, the final matching made the resulting groups comparable because all the standardized mean differences were below $20 \%$. The only differences between the 2 groups concerned are technical: patients in VKA group received more commonly complete ring but lower chordal implantation (Table 1), even if the standardized difference between the 2 groups concerning complete ring implantation was slightly under $20 \%$. However, these unbalanced variables had no influence on the clinical outcomes.

The overall rate of arterial complication was $1.7 \%(19$ cases) with no differences between groups $(\mathrm{n}=6[2.1 \%$ APLT $]$ vs $\mathrm{n}=13[1.6 \% \mathrm{VKA}] ; P=.50$ ), but patients treated with APLT had a significantly lower incidence of major bleeding complications than the VKA group, (overall $\mathrm{n}=32[2.8 \%]$ and $\mathrm{n}=2[0.7 \%]$ APLT vs $\mathrm{n}=30[3.9 \%]$ VKA; $P=.01$ ) (Table 2); this finding was mainly due to patients experiencing hemoglobin drop $>3 \mathrm{~g} / \mathrm{dL}$ or necessitating blood transfusion (Figure 2).

In the matched cohort, 6-month mortality was $2.1 \%$ (24 cases), significantly higher in patients treated with VKA than APLT drugs $(\mathrm{n}=1[0.3 \%]$ APLT vs $\mathrm{n}=23[2.7 \%]$ VKA; $P=.02$ ) (Table 2); this result was mainly due to the association between VKA therapy and major bleeding: mortality occurred in 3 patients $(9.4 \%)$ with major bleeding versus 21 patients $(1.9 \%)$ without major bleeding $(P=.027)$. Stratifying in 4 groups according to the type of therapy and occurrence of major bleeding, mortality occurred in $0.4 \%$ of APLT group patients without major bleeding, in none of the APLT group patients with major bleeding, in $2.4 \%$ of the VKA group patients without major bleeding, and in $10 \%$ of the VKA group patients with major bleeding $(P=.03)$.

\section{Multivariable Analyses in the Matched Cohort}

VKA therapy was confirmed to be associated with higher likelihood of major bleeding along with ischemic time (ie, crossclamp time) and female gender (Table 3); moreover, VKA therapy was associated with a higher rate of 6-month mortality, along with age and creatinine (Table 3).

\section{DISCUSSION}

We performed the largest study to date regarding the incidence of short-term thromboembolic and hemorrhagic complications in patients undergoing MVR. We demonstrated 
TABLE 1. Patient characteristics in matched cohorts

\begin{tabular}{|c|c|c|c|c|}
\hline & $\begin{array}{l}\text { Antiplatelet therapy group } \\
\qquad(\mathbf{n}=\mathbf{2 8 6})\end{array}$ & $\begin{array}{l}\text { Vitamin } \mathrm{K} \text { antagonist group } \\
(\mathbf{n}=\mathbf{8 5 8})\end{array}$ & $P$ value & $\begin{array}{c}\text { Standardized } \\
\text { difference }(\%)\end{array}$ \\
\hline Female gender & $106(37.1)$ & $319(37.2)$ & .97 & 0.21 \\
\hline Age $(y)$ & $56.3 \pm 17.3$ & $57.7 \pm 12.9$ & .22 & 13.1 \\
\hline Body mass index & $25.4 \pm 4.0$ & $25.0 \pm 4.8$ & .15 & 9.0 \\
\hline Chronic obstructive pulmonary disease & $29(10.1)$ & $61(7.1)$ & .20 & 10.7 \\
\hline Malignancy & $5(1.7)$ & $24(2.8)$ & .33 & 7.4 \\
\hline Prior stroke & $5(1.7)$ & $11(1.3)$ & .56 & 3.3 \\
\hline Other than cerebrovascular disease & $8(2.8)$ & $13(1.5)$ & .16 & 9.0 \\
\hline Hypertension & $145(50.7)$ & $404(47.1)$ & .29 & 7.2 \\
\hline Noninsulin dependent diabetes mellitus & $12(4.2)$ & $30(3.5)$ & .59 & 3.6 \\
\hline Insulin dependent diabetes mellitus & $4(1.4)$ & $12(1.4)$ & 1.00 & 0 \\
\hline Peripheral vascular disease & $11(3.9)$ & $24(2.8)$ & .37 & 6.1 \\
\hline Previous gastrointestinal bleeding & $7(2.4)$ & $17(2.0)$ & .63 & 2.7 \\
\hline Creatinine (mg/dL) & $0.90 \pm 0.22$ & $0.90 \pm 0.23$ & .54 & 0 \\
\hline Closed ring & $165(58.3)$ & $583(67.9)$ & $<.001$ & 19.9 \\
\hline Resective plasty & $118(41.3)$ & $376(43.8)$ & .45 & 5.0 \\
\hline Chordal implantation & $70(24.5)$ & $84(9.8)$ & $<.001$ & 39.7 \\
\hline Chordal transposition & $6(2.7)$ & $14(1.6)$ & .64 & 7.6 \\
\hline Edge-to-edge & $33(11.5)$ & $108(12.6)$ & .64 & 3.4 \\
\hline Cardiopulmonary bypass time (min) & $109.7 \pm 27.8$ & $109.6 \pm 34.7$ & .96 & 0.3 \\
\hline Crossclamp time (min) & $83.0 \pm 22.1$ & $82.3 \pm 28.9$ & .72 & 2.7 \\
\hline
\end{tabular}

Values are presented as mean \pm standard deviation or $\mathrm{n}(\%)$.

that thromboembolic complications are rare, with an overall incidence of $1.4 \%$ during the first 6 months after surgery. The type of antithrombotic therapy did not influence arterial thromboembolic complications.

A higher incidence of major bleeding was also observed in patients receiving oral anticoagulants during the first 3 months. In addition, the incidence of hemorrhagic complications was relatively more frequent (overall, 2.8\%) than thromboembolic ones.

The relevance of these findings is not negligible because most of the information available in the literature for patients undergoing MVR are gathered from large series with long-term follow-up. David and colleagues ${ }^{10}$ reported 50 thromboembolic events $(10.2 \%)$ out of 488 patients during 15 years of follow-up. Carpentier and colleagues ${ }^{11}$ described only 4 thromboembolic events in his original series of 162 patients followed for 29 years $(2.5 \%)$. In both series patients underwent anticoagulation therapy with VKA during the first 3 and 2 months, respectively, and the incidence of thromboembolic or hemorrhagic complications during the early period after surgery was not specified. Postoperative oral anticoagulation therapy should theoretically abolish the risk of thrombosis on newly implanted prosthetic material and scarred tissue, avoiding systemic embolization. However, oral anticoagulation therapy carries a bleeding risk, and such hemorrhagic events associated with this therapy are not insignificant. Adequately powered trials have clearly demonstrated that a higher

TABLE 2. Outcomes in matched cohorts

\begin{tabular}{|c|c|c|c|}
\hline & $\begin{array}{l}\text { Antiplatelet therapy group } \\
\qquad(\mathrm{n}=\mathbf{2 8 6})\end{array}$ & $\begin{array}{l}\text { Vitamin K antagonist group } \\
(\mathbf{n}=\mathbf{8 5 8})\end{array}$ & $P$ value \\
\hline Length of stay (d) & $7(6-9)$ & $7(6-8)$ & .45 \\
\hline Arterial complications & $6(2.1)$ & $13(1.6)$ & .50 \\
\hline Cardiac valvular or mural thrombus & 0 & $2(0.2)$ & 1.00 \\
\hline Ischemic stroke & $3(1.0)$ & $9(1.0)$ & 1.00 \\
\hline Transient ischemic attack & $1(0.3)$ & $6(0.7)$ & .51 \\
\hline Peripheral thromboembolism & $1(0.3)$ & $1(0.1)$ & .44 \\
\hline Major bleeding complications & $2(0.7)$ & $30(3.9)$ & .01 \\
\hline Hemorrhagic stroke & $1(0.3)$ & $5(0.6)$ & .64 \\
\hline Symptomatic bleeding into critical organ & 0 & $8(0.9)$ & .21 \\
\hline Drop in hemoglobin $>3 \mathrm{~g} / \mathrm{dL}$ or necessitating blood transfusion & $2(0.7)$ & $27(3.1)$ & .02 \\
\hline Fatal bleeding & 0 & $2(0.2)$ & .41 \\
\hline 6-mo Mortality & $1(0.3)$ & $23(2.7)$ & .02 \\
\hline
\end{tabular}

Values are presented as median (range) or $\mathrm{n}(\%)$. 


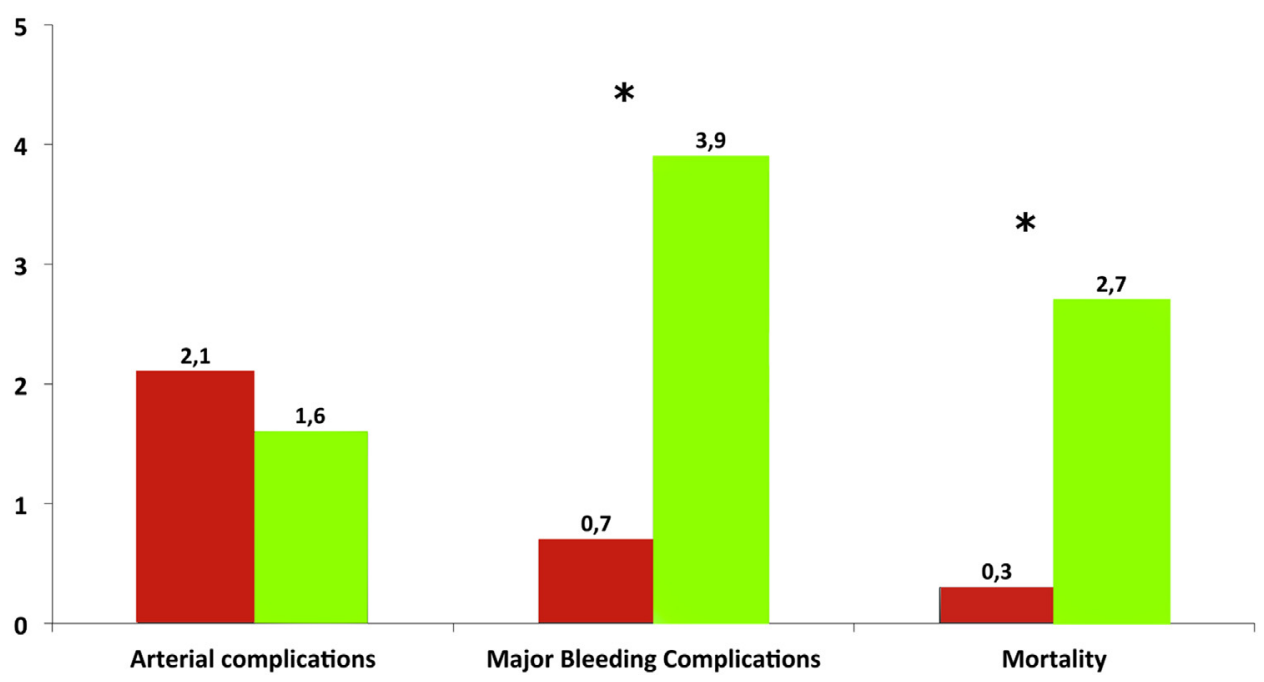

FIGURE 2. Main 6-month events in vitamin $\mathrm{K}$ antagonist (green columns) and antiplatelet therapy (red columns) in matched cohorts. $* P<.05$.

rate of major bleeding is directly related to increased risk of death. ${ }^{12}$ Our observation of major bleeding events during the first 3 months of oral anticoagulation therapy is in accordance with previous publications. Recently, the Randomized, Phase II Study to Evaluate the Safety and Pharmacokinetics of Oral Dabigatran Etexilate in Patients After Heart Valve Replacement (RE-ALIGN) trial ${ }^{13}$ (conducted among patients with prosthetic heart valves) reported major bleeding complications in $2 \%$ of patients during the first 3 months. Major bleeding complications were found in $2.8 \%$ in patients receiving warfarin therapy during the first 3 months following mitral valve replacement with bioprosthesis. ${ }^{14}$

Guidelines are discordant in their recommendations for antithrombotic prophylaxis during the first 3 months following MVR. In 2008, the Committee of the European Association of Cardio-Thoracic Surgery produced guidelines on antiplatelet and anticoagulation management in cardiac surgery. ${ }^{15}$ This document included a specific chapter for anticoagulation during the first 3 months after MVR; it takes into consideration the few studies reporting

TABLE 3. Multivariate analyses in the matched cohort

\begin{tabular}{|c|c|c|c|}
\hline & Odds ratio & $\begin{array}{c}95 \% \\
\text { Confidence } \\
\text { interval }\end{array}$ & $P$ value \\
\hline \multicolumn{4}{|l|}{ 6-mo Major bleeding* } \\
\hline Vitamin $\mathrm{K}$ antagonist therapy & 5.2 & $1.2-15.7$ & .03 \\
\hline Female gender & 2.5 & $1.2-5.1$ & .01 \\
\hline Crossclamp time (min) & 1.02 & $1.01-1.03$ & .04 \\
\hline \multicolumn{4}{|l|}{ 6-mo Mortality $\dagger$} \\
\hline Vitamin $\mathrm{K}$ antagonist therapy & 11.1 & $1.4-25.2$ & .02 \\
\hline Age (y) & 1.09 & $1.05-1.14$ & $<.01$ \\
\hline Creatinine $(\mathrm{mg} / \mathrm{dL})$ & 6.4 & $2.2-15.7$ & $<.01$ \\
\hline
\end{tabular}

*Area under the curve of the model was 0.75 . $\dagger$ Area under the curve of the model was 0.86 . thrombembolic events and a Best Evidence Topic review published by Dunning and colleagues. ${ }^{16}$ The Committee recommendations are most influenced by the Dunning review, ${ }^{16}$ which supported warfarin anticoagulation therapy during the first 3 months after MVR. The 2012 joint European Society of Cardiology/European Association for Cardio-Thoracic Surgery guidelines ${ }^{5}$ on heart valve disease recommend oral anticoagulation during the first 3 months after MVR (Class IIa, Level C) with no references supporting the recommendation. In 2012, the American College of Chest Physicians guidelines on antithrombotic therapy suggested antiplatelet therapy for the first 3 months after MVR in patients in sinus rhythm (Grade 2C). ${ }^{6}$ This recommendation is based on a single retrospective study by Aramendi and colleagues ${ }^{17}$ who reported on the thromboembolic risk of 235 patients undergoing mitral replacements or repairs from 1990 to 1995 . In total, 6 episodes of thromboembolism were reported. All occurred during the first postoperative year, and 4 of these events occurred during the first 3 months of follow-up. Two patients were taking ticlopidine and 4 were taking warfarin.

More recently Schwann and colleagues ${ }^{18}$ performed a single-center, retrospective evaluation of 249 patients who underwent MVR (144 patients) or replacement with bioprosthesis (105 patients), including also patients receiving concomitant procedures such as coronary artery bypass grafting, aortic bioprosthesis implants, and atrial fibrillation surgery. Patients discharged taking warfarin $(77 \%)$ were compared with those discharged without warfarin; no difference in thromboembolic or hemorrhagic events was demonstrated.

Suri and colleagues ${ }^{19}$ recently reported on 13,082 patients from the Society of Thoracic Surgeons Database undergoing mitral valve repair in North America from 2008 to 2010. Their study aimed to determine the incidence and predictors 
of VKA use immediately after isolated MVR. They showed an extreme variability in VKA prescription, which is predominantly driven by surgeon or center preference rather than patients' clinical variables. VKA prescription was associated with a significantly longer length of stay in hospital after surgery. No data regarding thromboembolic or hemorrhagic complications were available in this study. Based on the paucity of information from published series on the shortterm antithromboembolic prophylaxis after MVR, our findings are consistent with the need of reappraisal in terms of adequate therapeutic strategies and effects.

Several limitations should be emphasized regarding our study: the retrospective nature of data collection and the absence of randomized criteria for treatment allocation, antithrombotic prophylaxis chosen mainly by center or surgeon's preference, the lack of information regarding the incidence of atrial fibrillation after the operation, the international normalized ratio values at the time of bleeding or thrombotic events and the time in therapeutic range, and the limited number of patients receiving aspirin therapy.

Propensity scores are often used to reduce bias in observational and retrospective studies. $^{20,21}$ Ideally, a prospective, randomized controlled trial should be performed comparing warfarin therapy to APLT during the first 3 months after MVR. However, given the small number of events occurring in the short period of observation after surgery, such a trial would be difficult to perform. In our study, overall arterial and bleeding complications rate was $0.7 \%$ and $3.9 \%$, respectively. Accordingly, more than 5000 patients per group would be needed to obtain a $95 \%$ confidence interval lower than $1 \%$ under the hypothesis of similar arterial and bleeding event rates between treatment arms. While we wait for such an endeavour to be accomplished, our study offers the best evidence so far regarding the initial antithrombotic prophylaxis in patients undergoing mitral valve repair. We observed similar thromboembolic rates for patients undergoing isolated MVR who are at low risk of thromboembolic complications. Given that the incidence of hemorrhagic complication in our series was double the incidence of thromboembolic events, these data should be considered when choosing antithrombotic therapy in these patients. Compared with previous publications, we selected a large and homogeneous group of patients, excluding concomitant procedures that might lead to a different clinical profile (ie, coronary artery disease and risk of atherosclerosis-related events as well as atrial fibrillation ablation surgery) and carefully excluding patients with preoperative chronic, paroxysmal, or permanent atrial fibrillation.

\section{Conflict of Interest Statement}

Authors have nothing to disclose with regard to commercial support.
Gruppo Italiano di Ricerca Outcome in Cardiochirurgia Investigators include Crescenzia Rotunno; Ziv Beckerman; Luigi Martinelli, MD; Marco Lanfranconi; Davide Foresti; Egidio Varone, MD; Giuseppe Punta, MD; Ottavio Alfieri, MD; Elisabetta Lapenna, MD; Gennaro Ismeno, MD; Achille Pulcino, MD; Francesco Alamanni, MD; Margherita Dalla Tomba, MD; Giuseppe Coletti, MD; Enrico Vizzardi, MD; Antonio Lio, MD; Marco Solinas, MD; and Massimiliano Foschi, MD.

\section{References}

1. Iung B, Baron G, Butchart EG, Delahaye F, Gohlke-Bärwolf C, Levang OW, et al. A prospective survey of patients with valvular heart disease in Europe: the Euro Heart Survey on Valvular Heart Disease. Eur Heart J. 2003;24: 1231-43.

2. Nishimura RA, Otto CM, Bonow RO, Carabello BA, Erwin JP III, Guyton RA, et al. 2014 AHA/ACC guideline for the management of patients with valvula heart disease: executive summary: a report of the American College of Cardiology/American Heart Association Task Force on Practice Guidelines. J Am Coll Cardiol. 2014;63:2438-88.

3. Paparella D, Guida P, Bisceglia L, Caparrotti S, Carbone C, Cassese M, et al. Development and results of Puglia adult cardiac surgery registry. J Cardiovasc Med (Hagerstown). 2014;15:810-6.

4. Helder MR, Schaff HV, Dearani JA, Li Z, Stulak JM, Suri RM, et al. Management of mitral rigurgitation in Marfan syndrome: outcomes of valve repair versus replacement and comparison with myxomatous mitral valve disease. J Thorac Cardiovasc Surg. 2014;148:1020-4.

5. Joint Task Force on the Management of Valvular Heart Disease of the European Society of Cardiology (ESC); European Association for Cardio-Thoracic Surgery (EACTS), Vahanian A, Alfieri O, Andreotti F, Antunes MJ, Barón-Esquivias G, Baumgartner H, et al. Guidelines on the management of valvular heart disease (version 2012). Eur Heart J. 2012;33: 2451-96.

6. Whitlock RP, Sun JC, Fremes SE, Rubens FD, Teoh KH. American College of Chest Physicians. Antithrombotic and thrombolytic therapy for valvular disease: Antithrombotic Therapy and Prevention of Thrombosis, 9th ed: American College of Chest Physicians Evidence-Based Clinical Practice Guidelines. Chest. 2012;141(2 Suppl):e576S-600.

7. Mehran R, Rao SV, Bhatt DL, Gibson CM, Caixeta A, Eikelboom J, et al. Standardized bleeding definitions for cardiovascular clinical trials: a consensus report from the Bleeding Academic Research Consortium. Circulation. 2011;123: 2736-47.

8. Schulman S, Kearon C, Subcommittee on Control of Anticoagulation of the Scientific and Standardization Committee of the International Society on Thrombosis and Haemostasis. Definition of major bleeding in clinical investigations of antihemostatic medicinal products in non-surgical patients. J Thromb Haemost. 2005;3:692-4.

9. Austin PC. Optimal caliper widths for propensity-score matching when estimating differences in means and differences in proportions in observational studies. Pharm Stat. 2011;10:150-61.

10. David TE, Ivanov J, Armstrong S, Rakowski H. Late outcomes of mitral valve repair for floppy valves: implications for asymptomatic patients. J Thorac Car diovasc Surg. 2003;125:1143-52.

11. Braunberger E, Deloche A, Berrebi A, Abdallah F, Celestin JA, Meimoun P, et al Very long-term results (more than 20 years) of valve repair with Carpentier's techniques in nonrheumatic mitral valve insufficiency. Circulation. 2001;104 I8-11.

12. Yusuf S, Mehta SR, Chrolavicius S, Afzal R, Pogue J, Granger CB, et al. Comparison of fondaparinux and enoxaparin in acute coronary syndromes. $N$ Engl $J$ Med. 2006;354:1464-76.

13. Eikelboom JW, Connolly SJ, Brueckmann M, Granger CB, Kappetein AP Mack MJ, et al. Dabigatran versus warfarin in patients with mechanical heart valves. N Engl J Med. 2013;369:1206-14.

14. Colli A, D'Amico R, Mestres CA, Pomar JL, Camara ML, Ruyra X, et al. Is early antithrombotic therapy necessary after tissue mitral valve replacement? J Heart Valve Dis. 2010;19:405-11.

15. Dunning J, Versteegh M, Fabbri A, Pavie A, Kolh P, Lockowandt U, et al EACTS Audit and Guidelines Committee. Guideline on antiplatelet and anticoagulation management in cardiac surgery. Eur J Cardiothorac Surg. 2008;34:73-92. 
16. Asopa S, Patel A, Dunning J. Is short-term anticoagulation necessary after mitral valve repair? Interact Cardiovasc Thorac Surg. 2006;5:761-5.

17. Aramendi JL, Agredo J, Llorente A, Larrarte C, Pijoan J. Prevention of thromboembolism with ticlopidine shortly after valve repair or replacement with a bioprosthesis. J Heart Valve Dis. 1998;7:610-4.

18. Schwann TA, Engoren M, Bonnell M, Clancy C, Khouri S, Kabour A, et al. Mitral valve repair and bioprosthetic replacement without postoperative anticoagulation does not increase the risk of stroke or mortality. Eur J Cardiothorac Surg. 2013;44:24-31

19. Suri RM, Thourani VH, He X, Brennan JM, O'Brien SM, Rankin JS, et al Variation in warfarin thromboprophylaxis after mitral valve repair: does equi- poise exist and is a randomized trial warranted? Ann Thorac Surg. 2013;95 1991-8.

20. D'Agostino RB Jr. Propensity scores in cardiovascular research. Circulation 2007; 115:2340-3

21. Rubin DB. Using multivariate matched sampling and regression adjust ment to control bias in observational studies. J Am Stat Assoc. 1979; $74: 318-24$.

Key Words: mitral valve repair, anticoagulation, bleeding, stroke, antiplatelet

Readers who found these articles interesting may also like to read the following papers found in recent and future issues of our sister publications, Seminars in Thoracic and Cardiovascular Surgery and Operative Techniques in Thoracic and Cardiovascular Surgery!

\section{Acquired: Valvular Heart Disease}

Original Submission: Posterior Leaflet Detachment, Augmentation, and Reconstruction for Treatment of Functional Mitral Valve Regurgitation. Rakesh M. Suri. Semin Thorac Cardiovasc Surg 2015; Summer; 27(2):91-94.

Editorial Commentary: Patch Augmentation of Mitral Valve Leaflet in Ischemic Mitral Regurgitation. Tirone E. David. Semin Thorac Cardiovasc Surg 2015; Summer; 27(2):95-96.

Original Submission: Elevated Stroke Risk Associated with Femoral Artery Cannulation During Mitral Valve Surgery. Kareem Bedeir. Semin Thorac Cardiovasc Surg 2015; Summer; 27(2):97-103.

Editorial Commentary: Are We Going Backwards or Forwards in Minimally Invasive Mitral Valve Surgery? Three Eras of Perfusion Strategy. Vinay Badhwar. Semin Thorac Cardiovasc Surg 2015; Summer; 27(2):104-105.

Current Readings: Selection of Valve Prostheses. Cristian Rosu. Semin Thorac Cardiovasc Surg 2015; Summer; $27(2): 152$.

State of the Art: Strategies and Devices to Minimize Stroke in Adult Cardiac Surgery. Richard M. Engelman. Semin Thorac Cardiovasc Surg 2015; Spring; 27(1):24-29.

State of the Art: Minimally Invasive Valve Surgery: When Less is More. Joseph Lamelas. Semin Thorac Cardiovasc Surg 2015; Spring; 27(1):49-56.

Discussion in Cardiothoracic Treatment and Care: Surgical Ablation for Atrial Fibrillation. Marc Gillinov. Semin Thorac Cardiovasc Surg 2015; Spring; 27(1): 65-79.

Original Submission: Hemodynamic performance of the aortic valve late after David I: An echocardiographic study. Antonino Rubino. Expected Publication December 2015.

Editorial Commentary: Back to David I. Tirone David. Semin Thorac Cardiovasc Surg 2015; Autumn; 27(3):264-265.

Discussion in Cardiothoracic Treatment and Care: Aortic Valve/Root Repair. Tirone David. Semin Thorac Cardiovasc Surg 2015; Autumn; 27(3):271-287.

Biatrial Transseptal Approach for Combined Mitral Valve and Tricuspid Valve Operations. Mahim Malik. Oper Tech Thorac Cardiovasc Surg 2015; Spring; 20(1):2-16.

Mitral Valve Replacement for Infective Endocarditis with Annular Abscess: Annular Reconstruction. Gregory J. Bittle. Oper Tech Thorac Cardiovasc Surg 2015; Spring; 20(1):17-30.

Reoperative Aortic Valve Replacement After Previous Coronary Artery Bypass Grafting or Aortic Valve Replacement. Marc R. Moon. Oper Tech Thorac Cardiovasc Surg 2014; Winter; 19(4):482-499.

Mitral Annuloplasty Using A Biodegradable Annuloplasty Ring. Sanjay Cherian. Oper Tech Thorac Cardiovasc Surg 2015; Summer; 20(2):124-134. 
APPENDIX 1. Propensity score model

\begin{tabular}{|c|c|c|c|}
\hline Variables & $\beta$ & Standard error & $P$ value \\
\hline Closed ring & -.627 & .241 & .009 \\
\hline Age & -.010 & .009 & .266 \\
\hline Female gender & .306 & .245 & .212 \\
\hline Chronic obstructive pulmonary disease & 1.342 & .323 & .000 \\
\hline Malignancy & -.308 & 630 & .625 \\
\hline Prior stroke & .902 & .771 & .242 \\
\hline Other than Cerebrovascular disease & -.226 & .810 & .781 \\
\hline Hypertension & .483 & .227 & .033 \\
\hline Noninsulin-dependent diabetes mellitus & -.089 & .585 & .879 \\
\hline Insulin-dependent diabetes mellitus & 2.149 & .586 & .000 \\
\hline Peripheral vascular disease & 1.076 & .604 & .075 \\
\hline Previous gastrointestinal bleeding & .293 & .655 & .655 \\
\hline Resective plasty & .496 & .241 & .040 \\
\hline Chordal implantation & .398 & .322 & .216 \\
\hline Edge-to-edge & 1.147 & .335 & .001 \\
\hline Chordal Transposition & -1.217 & .668 & .069 \\
\hline Creatinine & -.093 & .469 & .843 \\
\hline Body mass index & .007 & .027 & .783 \\
\hline Cardiopulmonary bypass time (min) & .005 & .006 & .423 \\
\hline Crossclamp time (min) & -.010 & .008 & .239 \\
\hline Center volume* & & & .000 \\
\hline Medium vs low & 3.247 & .372 & .000 \\
\hline High vs low & -2.907 & .256 & .000 \\
\hline Continent & & & .000 \\
\hline North America vs Europe & .635 & .561 & .257 \\
\hline Middle Asia vs Europe & 2.625 & .503 & .000 \\
\hline \multirow[t]{2}{*}{ Constant } & -.487 & .971 & .616 \\
\hline & Area under the curve & Standard error & \\
\hline Model & 0.96 & 0.004 & \\
\hline
\end{tabular}

*Low-volume center: $<50$ cases $(9$ centers), medium-volume center: $51-100$ cases ( 3 centers) and high-volume center: $>100$ cases $(7$ centers). 